\title{
Constituição de competências para a intervenção no processo saúde-doença da população: desafio ao educador de enfermagem
}

\author{
CONSTITUTION OF KNOWLEDGE FOR THE INTERVENTION OF HEALTHAND DISEASE PROCESSE OF \\ THE POPULATION: A CHALLENGE FOR EDUCATOR IN NURSING
}

CONSTITUCIÓN DE COMPETENCIAS PARALAINTERVENCIÓN DEL PROCESO DE SALUD-ENFERMEDAD DE LA POBLACIÓN: DESAFÍO A EL EDUCADOR DE ENFERMERÍA

\section{Cesar Cavalcanti Silva' ${ }^{1}$ Emiko Yoshikawa Egry ${ }^{2}$}

\begin{abstract}
RESUMO
Tomando como objeto de estudo a prática educativa ensino e avaliação - operada no Estágio Rural Integrado da Universidade Federal da Paraiba, os autores discutem sobre a centralidade dos conhecimentos nesta prática educativa e consideram a possibilidade de se implantar processos de ensino e avaliação transformadores, ancorados na abordagem pedagógica por

Competências. Propõem a utilização desta abordagem e da metodologia da TIPESC Teoria da Intervenção Práxica da Enfermagem em Saúde Coletiva como orientadores dos processos de formação de força de trabalho em saúde e, em particular de enfermagem, visando à constituição de sujeitos críticos e reflexivos que atendam aos requerimentos do Sistema Único de Saúde.
\end{abstract}

\section{PALAVRAS-CHAVE}

Pesquisa educacional em enfermagem. Pessoal de saúde. Avaliação educacional. Professor.

\begin{abstract}
Having as an object of study the educational practice teaching and evaluation - as carried out in the Estágio Rural Integrado of the Federal University of Paraiba, the researchers discuss the relevance of knowledge concerning this educational practice and consider the possibility of implementing processes of teaching and evaluation that may operate transformations. In order to reach this goal, their study is supported by the Competence pedagogical approach. They propose this approach and the methodology underlying TIPESC - Theory of Nursing Practical Intervention in Collective Health - as guiding lines for the processes of the formation and training of health professionals, particularly those in the area of nursing. This aims for the development of critical and reflexive personnel that may

\section{RESUMEN}

Tomando como objeto de estudio la práctica educativa (docencia y evaluación) operada en el Estagio Rural Integrado de la Universidade Federal da Paraiba, los autores discuten sobre la centralidad de los

conocimientos en esta práctica educativa y consideran la posibilidad de implantar procesos de docencia y evaluación transformadores basados en el abordaje pedagógico por competencias. Proponen la utilización de este abordaje y de la metodología de la TIPESC - Teoria de la Intervención Práxica de la Enfermeria en la Salud Colectiva como orientadores de los procesos de formación de fuerza de trabajo en la saludy, en particular, de enfermería, objetivando la constitución de sujetos críticos y reflexivos que atiendan a los requisitos del Sistema Único de Salud, en esta área.
\end{abstract} respond to the requirements of the Sistema Único de Saúde.

\section{KEYWORDS}

Nursing education research. Health personnel.

Educational measurement. Teacher.

\section{PALABRAS-CLAVE}

Investigacion en educacion de enfermeria. Personal de salud. Evaluacion education. Profesor.
1 Enfermeiro. Professor do Departamento de Enfermagem MédicoCirúrgica e Administração do DEMCA/UFPB. cesar@jpa.neoline.com.br

2 Enfermeira.Professora Titular do

Departamento de Enfermagem em Saúde Coletiva da Escola de Enfermagem da Universidade de São Paulo. Orientadora deste estudo.

emiyegry@usp.br 
(a) O presente estudo está inscrito dentro da linha de pesquisa "Bases teórico - metodológicas e conceituais da enfermagem em saúde coletiva" e constitui parte da tese de doutorado do autor a ser apresentada à Escola de Enfermagem da Universidade de São Paulo.

(b) A diferença da carga horária deve-se ao fato de que, no currículo do curso de medicina da UFPB, o ERI constitui uma das etapas do internato, cuja carga horária é previamente determinada por resolução específica.

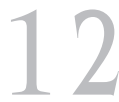

Rev Esc Enferm USP 2003; 37(2): 11-6.

\section{INTRODUÇÃO}

As contradições entre o discurso hegemônico do ensino e a prática profissional acentuam-se, à medida em que o Estado redefine as prioridades de atenção à saúde $\mathrm{e}$ a sociedade reclama um novo perfil profissional, diferente do forjado no paradigma tradicional. A superação destas contradições existentes, tanto nas políticas de saúde, como no ensino na área de saúde, deve passar, também, por um processo de reflexão coletiva dos agentes de ensino sobre seu trabalho de reprodução ideológica. ${ }^{(1)}$

O espaço de realização dos estágios curriculares supervisionados tem-se constituído num lugar privilegiado para se reconhecer essas contradições e promover transformações nas práticas educativas, de modo que, em contato com a realidade, os professores, os alunos e os profissionais de saúde dos serviços locais sejam despertados para a necessidade de se pensar acerca desta realidade.

É, pois, pertinente promoverem-se discussões mais aprofundadas na Universidade, particularmente na formação em Terceiro Grau das áreas profissionais da saúde sobre a possibilidade de implementação de processos pedagógicos transformadores, tais como o ensino baseado em competências, visando assim à produção de sujeitos críticos que atendam às necessidades de implantação efetiva do Sistema Único de Saúde - SUS.

O presente ensaio trata de se aproximarem os campos teóricos para a construção de categorias de análise para a investigação do objeto de estudo - a Prática Educativa no Estágio Rural Integrado da Universidade Federal da Paraíba ${ }^{(a)}$, descortinando-se as noções de: coletivo como objeto de intervenção das práticas de saúde; competência como centralidade nas práticas educativas e Teoria de Intervenção Práxica de Enfermagem em Saúde Coletiva - TIPESC, como marco teórico orientador da transformação.

\section{CENÁRIO E PROBLEMATIZAÇÃO DA PRÁTICA EDUCATIVA NO ERI}

A escolha do Estágio Rural Integrado da Universidade Federal da Paraíba - ERI/UFPB como cenário desta discussão, advém do fato de que este Estágio é uma atividade obrigatória para todos os alunos dos Cursos de Graduação da Área da Saúde do Campus I da UFPB e constitui a última etapa a ser cumprida antes da conclusão do curso. As atividades teórico-práticas são desenvolvidas em municípios conveniados do interior do Estado da Paraíba e procuram privilegiar a integração ensino x serviço. Estas características conferem ao ERI/UFPB a possibilidade de ser utilizado como um verdadeiro "laboratório" para experimentação de tecnologias alternativas nas práticas de ensino, na Área da Saúde, no âmbito da UFPB.

A obrigatoriedade do ERI está determinada pelo Regimento Interno do Centro de Ciências da Saúde - CCS, aprovado pelos Conselhos Universitário e de Ensino, Pesquisa e Extensão, por meio da Resolução $284 / 79^{(2)}$. A citada resolução determina, ainda, uma carga horária de 160 horas para os alunos dos Cursos de Enfermagem, Farmácia, Odontologia, Nutrição e Fisioterapia, e de 320 horas para os alunos do Curso de Medicina. ${ }^{(b)}$

Como pré-requisito para a realização deste estágio, os concluintes dos cursos do CCS/ UFPB são submetidos a um treinamento, no qual recebem informações sobre sua permanência nos municípios onde irão estagiar e a documentação necessária para sua inserção no sistema de saúde local.

Com o propósito de desenvolver uma perspectiva crítica do contexto sócio-político regional nos estagiários e nos profissionais de saúde do nível local, o ERI é, hoje, um braço vivo da UFPB, no que concerne às atividades de saúde extramuros, colocando-se, desta forma, na privilegiada posição de elo entre a Universidade, os serviços de saúde e as comunidades onde se insere.

O ERI está respaldado pela Lei 8080/90 (3), que prevê a criação de comissões permanentes de integração entre os serviços de saúde e as instituições de ensino, de modo a propor prioridades, métodos e estratégias para a formação de força de trabalho em saúde para o SUS.

Decorrida pouco mais de uma década, desde a aprovação da Lei Orgânica da Saúde, as instituições formadoras continuam lançando, no mercado de trabalho, um grande número de novos profissionais de nível su- 
perior que, na sua maioria, desconhecem ou não se interessam pelo que significa Reforma Sanitária e, muito menos, SUS, municipalização, universalidade e eqüidade. Isto indica que, com relação à formação de força de trabalho em saúde, para a sustentação dos programas de saúde, a contribuição das instituições de ensino tem sido mínima. ${ }^{(4)}$

Há experiências inovadoras e tentativas de reformulação na formação e capacitação de profissionais, na área da saúde, mas ainda não há, no campo do ensino para a formação de força de trabalho em saúde, procedimentos capazes de responder substantivamente aos interesses da Reforma Sanitária. ${ }^{(5)}$

Neste sentido, formados a partir de paradigmas educacionais descompassados com os requerimentos da nova formulação política e organizacional dos serviços e ações de saúde, e colocados desta forma no mercado de trabalho, estes novos profissionais de saúde dificilmente poderão atuar engajados e com uma visão crítica em relação aos pilares teóricos de sustentação do Sistema Único de Saúde, contribuindo para sua total efetivação.

Especificamente, na formação de enfermeiros, as práticas educativas freqüente-mente baseadas em planejamentos normativos e ancoradas em abordagens pedagógicas tradicionais, provocam conflito com a necessidade de se formar sujeitos críticos, reflexivos e questionadores, em resposta aos requerimentos do Sistema Único de Saúde.

O exercício da docência na UFPB, ministrando aulas teóricas e práticas no Curso de Graduação em Enfermagem e o exercício da supervisão de alunos no interior do Estado da Paraíba, junto ao Estágio Rural Integrado, desde 1987, permitem observar a utilização de práticas educativas tradicionais, amparadas em abordagens pedagógicas funciona-listas e a dificuldade da maioria dos alunos em exercitar a crítica da realidade de saúde dos municípios onde atuam, e, em conseqüência, contribuírem pouco para o processo de consolidação do SUS, no Estado.

\section{A INFLUÊNCIA DOS REFERENCIAIS PEDAGÓGICOS}

Segundo Valente ${ }^{(6)}$, nos dias atuais, a grande certeza na questão educacional como um todo é a urgência de se redefinir o papel das instituições escolares, no âmbito da formação.

Pinheiros, Rodrigues ${ }^{(7)}$ assinalam que as redefinições dos órgãos formadores perpassam a experimentação de novas tendências teóricas e de novas estratégias de ensino, nos processos formativos. Acreditam que a dificuldade de se implementarem transformações na prática profissional surge ainda na Graduação, adiantando que, se o ensino formal tem interesse de graduar profissionais questionadores e reflexivos, é fundamental que se repensem as práticas educativas e suas abordagens teóricas, além de que sejam fomentadas reflexões e discussões sobre o papel dos docentes e discentes nesses processos.

O ensino para a formação de profissionais de saúde orientados para os requerimentos do SUS pressupõe, entre outras ações, mudanças nas abordagens pedagógicas, $o$ que implica a revisão e compreensão do alcance de seus referenciais pedagógicos, cuja função é amparar teórica e ideologicamente as ações docentes.

A reflexão sobre as transformações necessárias nas práticas educativas tem importância estratégica, neste momento histórico, pois, dentre as transformações necessárias para a consolidação do SUS está a qualificação de seus trabalhadores, que pode convergir para esse objetivo ou distanciar-se dele, conforme o desenvolvimento das práticas educativas.

Especificamente, em relação à Enfermagem, considerando-se que esta profissão congrega um dos maiores contingentes da força de trabalho em saúde e configura-se como um importante segmento na luta pela consolidação do SUS, conforme afirma Egry ${ }^{(8)}$, é imperativo que o processo de formação de sua força de trabalho adote uma abordagem pedagógica diferenciada e práticas educativas transformadoras, baseadas nos pilares teóricos do SUS ${ }^{(c)}$, consubstanciados por seus princípios doutrinários e organizativos. competências para a intervenção no processo saúde-doença da educador da enfermagem
Constituição de população: desafio ao (c) A construção do SUS segue os princípios doutrinários da Universalidade, Equidade, Integralidade, Regionalização e Hierarquização, Resolubilidade, Descentralização, Participação dos Cidadãos $e$ Complementaridade do setor privado Ministério da Saúde ${ }^{(9)}$ 
César Cavalcanti Silva Emiko Yoshikawa Egry

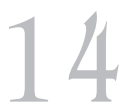

Rev Esc Enferm USP 2003; 37(2): 11-6.
Mendes ${ }^{(10)}$, assinala que defender princípios é mais fácil que aplicá-los, chamando a atenção para a formação de força de trabalho em saúde sensíveis aos princípios do SUS. O referido autor considera que o Sistema Único de Saúde não tem sido capaz de acompanhar a velocidade das transformações ocorridas no Brasil e no mundo e afirma que, sem rejeitar os pilares teóricos do SUS, é preciso reconhecer-se que sua materialidade depende de um conjunto de transformações.

Mandu, Almeida ${ }^{(1)}$ assinalam que fazer avançar os processos de formação, de modo que eles sejam compatíveis com os requerimentos dos processos de mudanças das ciências da saúde e, em particular, dos movimentos políticos de inclusão social, é o que se reclama no presente.

As autoras supra mencionadas prosseguem afirmando que o desafio que se coloca para a renovação das práticas educativas frente às necessidades sociais que se configuram na efetivação do SUS, é considerar o aspecto técnico necessário à viabilização do trabalho específico de enfermagem sem negligenciar as dimensões educativas e políticas como componentes capazes de dar suporte a uma intervenção práxica na prática profissional.

Segundo Antunes, Shigueno, Meneghin ${ }^{(12)}$, as práticas educativas carregam consigo uma ideologia e, por meio dos referenciais pedagógicos nas quais estão ancoradas, promovem e embasam as práticas do educando no sistema em que vive. A utilização do referencial conceitual da Medicina Comunitária e as implicações pedagógicas que marcaram o processo educativo de enfermagem, nas décadas de 70 e 80 do século XX, são exemplos clássicos dessa afirmação.

O modelo pedagógico posto em prática, naquele período, apontava para a integração das unidades formadoras de pessoal aos serviços de saúde, sem, contudo, considerar as diferenças sociais da população alvo e, muito menos, as competências demandadas naquele espaço. Isso propiciou a formação de profissionais de enfermagem acríticos, resultante de uma formação baseada no modelo preventivista, ancorado na multicausalidade e centrado na parcela do corpo social constituída pelos grupos sociais excluídos do cuidado médico privado. ${ }^{(13)}$

$\mathrm{Na}$ atualidade, a formação de força de trabalho em saúde e, em particular, de enfermagem, precisa acompanhar as transformações em curso no setor saúde, quer seja no plano macro das políticas sociais, quer seja nos micro espaços institucionais que interferem no processo saúde- doença, considerando-se sobretudo, os pilares teóricos de sustentação do SUS e o coletivo, como objeto de intervenção das práticas de saúde. Não se trata de superespecializar os trabalhadores, mas de prepará-los, desde a Graduação, para que sejam sensíveis aos problemas da realidade atual de saúde.

Apoiado em Bordenave, Antunes, Shigueno, Meneghin ${ }^{(12)}$ relatam que a escola pode optar pelo uso de três abordagens pedagógicas para a consecução das práticas educativas, no âmbito da formação de força de trabalho: o da transmissão de conhecimentos, o tecnicista ou de condicionamento e o da problematização da realidade, citando o primeiro como o mais amplamente difundido e utilizado pelos docentes na atualidade.

A abordagem pedagógica da transmissão de conhecimentos considera o aluno um receptáculo vazio, no qual conhecimentos externos são impressos, tendo como objetivo fundamental a transmissão de conceitos, idéias e procedimentos recebidos e adotados por repetição. ${ }^{(14)}$

A pedagogia conducionista ou tecnicista difere da anterior, por considerar mais importante o aprender a "fazer" e não o aprender a "saber". O principal objetivo dessa pedagogia é a formação de indivíduos eficientes do ponto de vista da produtividade, daí sua grande preocupação com a técnica. A prática educativa nesta abordagem procura ser o mais objetiva e operacional possível, o que explica as opções pelas técnicas do micro-ensino e da instrução programada. ${ }^{(14)}$

A abordagem da problematização da realidade procura superar a concepção do aluno como receptor de informações ou reprodutor de técnicas, para dar lugar ao aluno construtor do seu conhecimento, a partir da reflexão sobre sua própria prática. ${ }^{(14)}$

A análise destes modelos educacionais permite evidenciar que o repasse de conhecimentos aparece sempre como elemento central na operacionalização das três opções pedagógicas. A superação desta centralidade pode ocorrer pela adoção de um referencial pedagógico para a formação de força de trabalho em saúde que utilize o conhecimento, mas não se limite a ele. Neste novo modelo, os conhecimentos cedem lugar às competências como foco de atenção principal nas práticas educativas. 
Antunes, Shigueno, Meneghin ${ }^{(12)}$ apontam distorções nos processos de formação de força de trabalho em saúde, tanto no âmbito individual, quanto coletivo, que se manifestam como conseqüência do uso prolongado e dominante da opção pedagógica da transmissão de conhecimentos. Os autores relacionam no âmbito individual a passividade, a falta de atitude crítica, a relação dogmática com as fontes de informação, a valorização isolada do saber intelectual e o desinteresse para se transformar a realidade. No âmbito coletivo, relatam a ocorrência de grupos passivos e acríticos que adotam indiscriminadamente modelos e padrões de outras regiões, manipuláveis por comunicação de massa ou reprodutores de padrões historicamente estabelecidos e desvinculados do contexto social de sua realidade.

\section{A PRÁTICA EDUCATIVA NA FORMAÇÃO DE FORÇA DE TRABALHO EM SAÚDE EM UM NOVO ENFOQUE}

Conforme já foi salientado anteriormente, em termos pedagógicos, a prática educativa sempre oscilou entre os que optam apenas pela transmissão de conhecimentos e os que querem ligá-los imediatamente às práticas sociais. Como alternativa para superação dos modelos clássicos de ensino e avaliação centrados apenas na transmissão de conhecimentos, propõe-se a abordagem por Competências, estudada por Perrenoud ${ }^{(15)}$ e já amplamente difundida na França, Bélgica e Canadá.

Ao definir Competência como uma capacidade de agir eficazmente em um determinado tipo de situação, apoiado em conhecimentos, mas não exclusivamente neles, Perrenoud (15) estabeleceu uma diferença entre competências e conhecimentos.

Para este autor, enquanto os conhecimentos são representações da realidade que construímos e armazenamos ao sabor de nossa experiência e de nossa formação, as competências são capacidades para os utilizar, integrar ou mobilizar, visando à solução dos mais diversos problemas com os quais nos deparamos em nosso dia-a-dia.

A inserção da abordagem por Competências, como proposta para a formação em Terceiro Grau das áreas profissionais de saúde coloca para os docentes, na atualidade, a possibilidade de escolha entre duas formas de ensino e avaliação: uma prática educativa baseada apenas no repasse de conhecimentos, que não se preocupa com sua mobilização em certas situações, confiando na formação profissionalizante para construir competências, ou uma prática educativa que aceita limitar a quantidade de conhecimentos ministrados para exercitar, de maneira intensiva, sua mobilização em situações complexas.

Particularmente, para a formação de enfermeiros, o ensino baseado na abordagem por Competências pode responder a uma demanda social dirigida para o SUS, dado que toda competência está ligada a uma prática social de certa complexidade e evoca uma prática profissional instituída, emergente ou virtual. ${ }^{(15)}$

Para amparar as especificidades da abordagem por Competências, no plano pedagógico da constituição de força de trabalho em saúde, propomos a Metodologia da TIPESC - Teoria da Intervenção Práxica da Enfermagem em Saúde Coletiva, sistematizada por Egry ${ }^{(16)}$, como referencial pedagógico desta abordagem.

A utilização desta Metodologia, originariamente idealizado para a assistência e, atualmente, aplicado, tanto nesse âmbito quanto na investigação e na sistematização do processo ensino-aprendizagem, pode atender aos objetivos transformadores necessários à prática educativa voltada para a formação de Competências, pois caminha na direção contrária ao sentido unidirecional da relação educador-educando, que considera o primeiro como fonte inesgotável do saber e o segundo como mero depositário de conhecimentos técnicos normatizados. ${ }^{(17)}$

A Metodologia de Intervenção Práxica da Enfermagem em Saúde Coletiva - METISC propõe uma forma sistematizada para captar, interpretar e intervir nas práticas educativas, tendo em vista suas dimensões: a singular, a particular e a estrutural. A dimensão singular, relativa aos processos de ensino e avaliação, é aquela em que, em última instância, são operacionalizados os referenciais pedagógicos (dimensão particular) que levam o formando a integrar-se ao sistema em que vive, com resultados previsíveis sobre sua conduta posterior. Ambas articulam-se aos processos de produção e reprodução social da coletividade na qual se inserem, cujo contexto é historicamente determinado, constituindo assim, a dimensão estrutural. Depois da captação, interpretação e intervenção, segue-se a contínua reinterpretação do fenômeno, de forma práxica, constituindo a unidade dialética teoria-prática.
Constituição de competências para a intervenção no processo saúde-doença da população: desafio ao educador da enfermagem 
Recebido: 06/05/2002 Aprovado: 05/06/2003

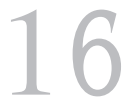

Rev Esc Enferm USP 2003; 37(2): 11-6.

\section{CONSIDERAÇÕES FINAIS}

As resistências internas de alguns docentes e as contradições verificadas no aparelho formador em relação às mudanças político-sociais geradas pela trajetória das estratégias rumo à unificação do sistema de saúde, levam a Universidade e particularmente, os cursos de saúde, a caminharem praticamente a reboque dos acontecimentos nesta área, gerando contradições que dificultam o processo de consolidação do SUS nos municípios conveniados com a UFPB, nos quais os alunos do CCS desenvolvem o ERI. Por tudo isso, as práticas educativas no âmbito dos cursos de Graduação em saúde requerem a experimentação de novas teorias pedagógicas e, sobretudo, a coragem para implementá-las.

A inspiração para mostrar a possibilidade de utilização de processos educativos trans-

\section{REFERÊNCIAS}

(1) Barros S, Egry EY. O Louco, a loucura e a alienação institucional: o ensino de enfermagem sub judice. São Paulo: Cabral Editora Universitária; 1996.

(2) Universidade Federal da Paraíba. Resolução 284/ 79, de 27 de Setembro de 1979. Aprova o regimento do Centro de Ciências da Saúde da Universidade Federal da Paraíba e dá outras providências. João Pessoa; 1979. /Mimeografado/.

(3) Brasil. Lei 8080 de 19 de Setembro de 1990. Dispõe sobre as condições para promoção, proteção e recuperação da saúde, a organização e o funcionamento dos serviços correspondentes e dá outras providências. In: Ministério da Saúde, Assessoria de Comunicação Social. Lei Orgânica da Saúde. Brasília, 1991.

(4) Garrafa V. Desafios éticos na política de recursos humanos frente às necessidades de saúde. Cad RH Saúde. 1993; 1(3): 9-18.

(5) Schraiber LB, Peduzzi M. Tendências e possibilidades da investigação de recursos humanos em saúde no Brasil. Educ Méd Salud 1993; 27(3): $295-313$.

(6) Valente SMP. Do currículo às diretrizes curriculares. Olho Mágico. 1999; 5(20): 6-7.

(7) Pinheiros VE, Rodrigues ARF. O processo ensino/aprendizagem na Enfermagem. Enferm Rev 1999; 5 (9/10): 62-79.

(8) Egry EY.O ensino da enfermagem em saúde coletiva diante do SUS: as transformações conceituais, metodológicas e pedagógicas no âmbito das escolas de enfermagem. São Paulo (SP): Escola de Enfermagem da USP; 1999. (Relatório de Pesquisa).

(9) Ministério da Saúde. Secretaria Nacional de Assistência à Saúde. ABC do SUS - Doutrinas e Princípios. Brasília; 1990. formadores, apoiados na abordagem por Competências, nos Cursos de Graduação da área da Saúde, e, particularmente da Enfermagem, origina-se do nosso desejo de contribuir para promover transformações no processo de formação de força de trabalho em saúde, de modo a ampliar seu alcance e tornar presente um futuro possível e desejável, que é a solução dos problemas relacionados com a carência de profissionais de saúde com perfis que atendam aos requerimentos do SUS, nesta área.

Uma prática profissional crítica, reflexiva e questionadora, consciente de suas raízes teóricas e filosóficas, dar-se-á quando esta mesma prática for exercida com Competência. Todavia, nenhuma transformação ocorrerá isoladamente, sem a correspondente e fundamental participação das instituições formadoras, unidas por práticas educativas diferenciadas, que preparem, desde logo, estes profissionais para o novo paradigma que se apresenta.
(10) Mendes EV. Uma nova agenda para a saúde. São Paulo: Hucitec; 1999.

(11) Mandu ENT, Almeida MCP. Necessidades em saúde: questões importantes para o trabalho da Enfermagem. Rev Brás Enferm 1999, 52 (1):54-66.

(12) Antunes MJM, Shigueno LYO, Meneghin P. Métodos pedagógicos que influenciaram o planejamento das ações educativas dos enfermeiros: Revisão Bibliográfica. Rev Esc Enferm USP 1999; 33 (2):165-174

(13) Salum MJL, Bertolozzi MR, Oliveira MAC. O coletivo como objeto do conhecimento e prática de enfermagem: as continuidades e descontinuidades da história. Departamento de Enfermagem em Saúde Coletiva. São Paulo Escola de Enfermagem da Universidade de São Paulo, s.d. / Mimeografado/.

(14) Bordenave JD. Alguns fatores pedagógicos. Brasília: 1994. [Apostila do curso de capacitação pedagógica para instrutor/ supervisor da Área da Saúde - Ministério da Saúde. Coordenação Geral de Desenvolvimento de Recursos Humanos para o SUS]

(15) Perrenoud P. Construir as competências desde a escola. Porto Alegre: Artes Médicas Sul; 1999.

(16) Egry EY. Saúde Coletiva: construindo um novo método em enfermagem. São Paulo: Ícone, 1996.

(17) Fonseca RMGS, Bertolozzi MR, Chiesa A M, Greco RM, Egry EY, Oliveira MACO. Desenvolvendo um processo ensino-aprendizagem: pressupostos e métodos de ensino da disciplina Enfermagem preventiva e comunitária do curso de graduação em enfermagem. Rev Esc Enferm USP 1992; 26 (3):419-26. 